\title{
Can previous acid etching increase the bond strength of a self-etching primer adhesive to enamel?
}

\section{Ana Paula Morales Cobra Carvalho(a) \\ Míriam Lacalle Turbino(b)}

\author{
(a) MSc in Orthodontics. \\ (b) PhD, Associate Professor, Department of \\ Restorative Dentistry, School of Dentistry, \\ University of São Paulo, São Paulo, SP, \\ Brazil.
}

\begin{abstract}
Because a greater research effort has been directed to analyzing the adhesive effectiveness of self etch primers to dentin, the aim of this study was to evaluate, by microtensile testing, the bond strength to enamel of a composite resin combined with a conventional adhesive system or with a self-etching primer adhesive, used according to its original prescription or used with previous acid etching. Thirty bovine teeth were divided into 3 groups with 10 teeth each $(\mathrm{n}=10)$. In one of the groups, a self-etching primer (Clearfil SE Bond - Kuraray) was applied in accordance with the manufacturer's instructions and, in the other, it was applied after previous acid etching. In the third group, a conventional adhesive system (Scotchbond Multipurpose Plus - 3M-ESPE) was applied in accordance with the manufacturer's instructions. The results obtained by analysis of variance revealed significant differences between the adhesive systems $(\mathrm{F}=22.31)$. The self-etching primer (Clearfil SE Bond) presented lower enamel bond strength values than the conventional adhesive system (Scotchbond Multipurpose Plus) $(\mathrm{m}=39.70 \pm 7.07 \mathrm{MPa}$ ) both when used according to the original prescription $(\mathrm{m}=27.81 \pm 2.64 \mathrm{MPa})$ and with previous acid etching $(\mathrm{m}=25.08 \pm 4.92 \mathrm{MPa})$.
\end{abstract}

Descriptors: Tensile strength; Dentin-bonding agents; Dental enamel.
Corresponding author:

Ana Paula Morales Cobra Carvalho

Rua Cantagalo, 630, apto. 102

São Paulo - SP - Brazil

CEP: 03319-000

E-mail:anapaula1007@hotmail.com or anapaula@anapaulacarvalho.odo.br 


\section{Introduction}

One of the purposes of research \& development in Dentistry is to contribute to a better clinical performance of dental materials. An increasing amount of research has been conducted with the purpose of developing adhesive systems with better quality and higher bond strengths to enamel and dentin, thus preventing restoration failure.

At present, adhesive systems can be divided into two groups: those that require previous acid etching, and self-etching adhesives.

Bonding to enamel is considered effective and presents high bond strength values. ${ }^{1}$ Nonetheless, the enamel bonding of self-etching adhesive systems has been questioned. ${ }^{2,3}$

The enamel surface is flat, without any mechanical retention, low wettability and low surface tension, thus being considered a poor substrate for bonding. Acid etching creates microscopic rugosities that provide micromechanical retention and increase surface tension.

Self-etching adhesives are a new concept in adhesion because of the acid primer that simultaneously provides acid etching and penetration into enamel and dentin. The effects of self-etching adhesives on enamel have been studied, and they produce a different etching pattern from the one produced by conventional adhesive systems in that the former presents a smaller quantity of microporosities. ${ }^{4} \mathrm{~A}$ lower degree of acid etching was observed for selfetching adhesives, nevertheless, with satisfactory bond strength values. ${ }^{5}$

The enamel bond strength of self-etching adhesives was lower than that of conventional adhesive systems. ${ }^{6}$ One in vitro research ${ }^{7}$ observed no statistical difference between the enamel bond strength of Clearfil Liner Bond 2 and that of conventional adhesive systems with previous acid etching. Observation by scanning electron microscopy showed that the use of conventional adhesive systems resulted in deeper etching patterns.

Because a greater research effort has been directed to analyzing the adhesive effectiveness of self etch primers to dentin, the aim of this study was to evaluate, by microtensile testing, the bond strength to enamel of a composite resin combined with a conventional adhesive system or with a self-etching primer adhesive, used according to its original prescription or with previous acid etching. An additional purpose was to confirm whether previous acid etching can improve the performance of the self-etching primer adhesive.

\section{Material and Methods}

Thirty freshly extracted bovine teeth, separated from their root portions, were used in this study since research has confirmed the suitability of their application as a substitute for human enamel in bonding tests. ${ }^{7}$ The next step was to flatten the buccal surfaces of the teeth in a water-cooled mechanical grinder (Politriz-Buehler, Boston, MA, USA), using 600 grit $\mathrm{Al}_{2} \mathrm{O}_{3}$ abrasive paper. After this, they were stored in distilled water.

The teeth were divided into 3 groups with 10 teeth each $(\mathrm{n}=10)$, as follows:

- Group 1 - Application of Clearfil SE Bond (Kuraray Co., Osaka, Japan), in accordance with the manufacturer's instructions (10 seconds of first bottle with acid and primer and 10 seconds of second bottle with adhesive and light polymerized for 10 seconds).

- Group 2 - Previous enamel etching with 37\% phosphoric acid, washing with water, drying, followed by the application of Clearfil SE Bond (Kuraray Co., Osaka, Japan), in accordance with the manufacturer's instructions.

- Group 3 - Application of Scotchbond Multipurpose Plus (3M-ESPE, St. Paul, MN, USA), in accordance with the manufacturer's instructions (light polymerized for 10 seconds).

The adhesive systems were light polymerized for 10 seconds with a light curing unit (Degulux Soft Start - Degussa Hills, Hanau, Germany) with $550 \mathrm{~mW} / \mathrm{cm}^{2}$. After that, the Filtek Z-250 (3M ESPE, St. Paul, MN, USA) composite resin was inserted in 4 increments of $1 \mathrm{~mm}$ each and light polymerized for 40 seconds. A silicon based impression material (Optosil, Heraeus Kulzer GmbH \& Co., KG, Germany) was used as a matrix measuring $5 \times 5 \mathrm{~mm}$.

In order to obtain the specimens, the teeth were mounted in an acrylic resin base. Then the resin composite and tooth structure were cut with a dia- 
mond disc in the cervico-occlusal and mesiodistal directions. The specimens presented a rectangular cross-sectional area of approximately $1 \mathrm{~mm}^{2}$. For this purpose, the Lab Cut 1010 machine (Extec Corp. - Enfield, CT, USA) was used with a diamond disc (Extec corp. - Enfield, CT, USA), at a speed of $250 \mathrm{rpm}$ for the mesiodistal cut and $125 \mathrm{rpm}$ for the cervico-occlusal cut. Only the 4 central specimens per tooth were used for the microtensile bond test.

The resin composite increments were inserted so that the proportion between the tooth structure and the resin composite length was maintained. Thus, a pattern was created to avoid any influence that might be caused by different dimensions of the 2 extremities when stress was applied during the microtensile test.

The specimens were then fixed with cyanoacrylate adhesive on each side, (Super Bonder Gel, Loctite, São Paulo, SP, Brazil) in the Geraldeli device, ${ }^{8}$ which was used for the microtensile bond test. Thus, the bond area was placed perpendicular to the direction of the stress applied. The specimen device was mounted in the universal test machine Mini Instron model 4442 (Instron - Canton, CT, USA) submitting it to stress at a speed of $0.5 \mathrm{~mm} / \mathrm{min}$.

After the microtensile test, the fractures at the bond interface were measured with a caliper and then the bond strength values were transformed into $\mathrm{MPa}$. With this methodology, the bond strength values were obtained according to the cross-sectional specimen areas. The values were submitted to statistical analysis of variance (ANOVA) and to the Newman-Keuls test.

The original results consisted of 120 bond strength values in MPa related to 30 teeth, with 4 specimens per tooth. Furthermore, only specimens with adhesive fracture were used for the statistics.

Table 1 - Enamel microtensile bond strength values of the two adhesive systems polymerized by halogen light and LED.

\begin{tabular}{l|c}
\hline \multicolumn{1}{c|}{ Groups } & Bond strength \\
\hline Self-etch primer & $27.81 \pm 2.64 \mathrm{MPa}$ \\
\hline Self-etch primer with phosphoric acid & $25.08 \pm 4.92 \mathrm{MPa}$ \\
\hline Scotchbond Multipurpose Plus & $39.70 \pm 7.07 \mathrm{MPa}$ \\
\hline
\end{tabular}

Next, the mean of these values was calculated, resulting in 30 values, 10 for each group.

\section{Results}

The results obtained by analysis of variance revealed significant differences between the adhesive systems $(F=22.31)$. After comparison between the measurements using the Newman-Keuls test, it was observed that the adhesive Scotchbond Multipurpose Plus ( $\mathrm{m}=39.70 \pm 7.07 \mathrm{MPa}$ ) presented a higher bond strength value than the self-etching primer Clearfil SE Bond. There was no statistically significant difference between the self-etching primer Clearfil SE Bond applied in accordance with the manufacturer's instructions $(\mathrm{m}=27.81 \pm 2.64 \mathrm{MPa})$ and with previous acid etching $(\mathrm{m}=25.08 \pm 4.92 \mathrm{MPa})$. (Table 1 and Graph 1)

\section{Discussion}

Because of the increasing application and marketing of self-etching primers, it is necessary to confirm their efficacy in bonding to tooth structures. The acidic primer of these systems promotes selective dissolution of enamel prisms, creating microporosities for resin penetration. Some studies with self-etching primers obtained bond strengths lower than or the same as those of conventional one-bottle adhesive systems with previous acid etching. This occurred due to resin failure, because the primer did

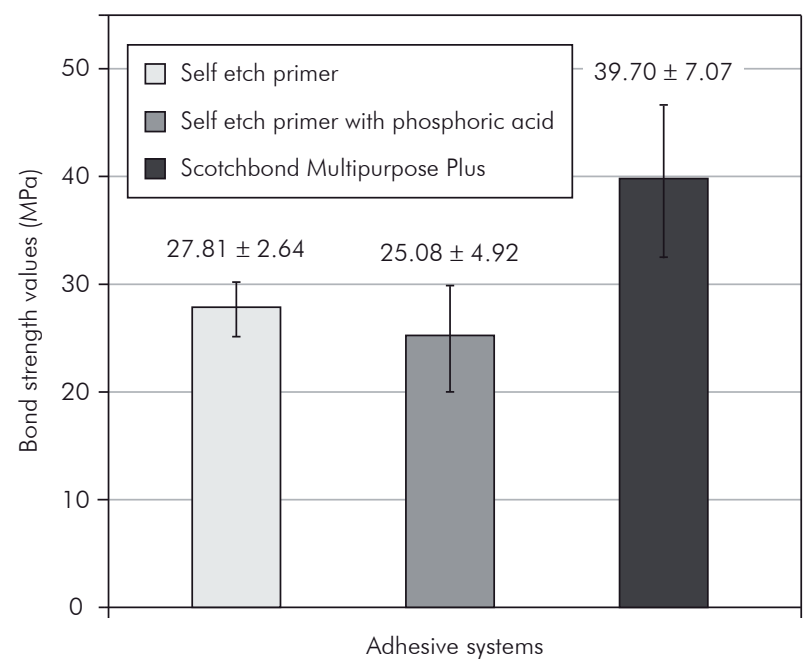

Graph 1 - Enamel microtensile bond strength values of the adhesive systems (values in MPa). 
not penetrate deeply enough between the enamel crystallites and rods. Consequently, the bond between enamel and resin fails after some time of function in the mouth. ${ }^{9,10}$

Some studies observed that self-etching primers did not create a deep etch pattern, differently from the phosphoric acid application only. ${ }^{3}$ Empty areas in the hybridized enamel region at the enamel-resin interface were also observed. ${ }^{11}$

The balance between demineralization depth and extent of monomer penetration of the self-etching primers is the key to a good quality bond between enamel and resin. ${ }^{12}$

In another study with self-etching primers, ${ }^{13}$ there was a decreasing quantity of adhesive at the enamel-resin interface, from the resin to the enamel area. Moreover, the deepest areas in the demineralized enamel had poor adhesive saturation.

Other studies showed that self-etching primers did not prevent infiltration when applied with previous acid etching. ${ }^{14,15}$

Due to the large number of studies that have shown lower bond values to enamel for self-etching primers, the purpose of this study was to test the application of Clearfil SE Bond with previous acid etching compared with application in accordance with the manufacturer's instructions, and, after this, to compare the results with those of a conventional adhesive system. The purpose was to evaluate whether acid etching could promote higher enamel bond strength. The results showed no significant differences between the evaluated patterns. This suggests that even with the larger number of microretentions created by acid etching, primer penetration into these microretentions was not effective and did not result in higher bond strength values.

Self-etching primers have limited demineralization and impregnation depths because of wet dentin and the ionic effects of high calcium and phosphate concentrations, which limit the dissolution of apatite crystals. ${ }^{16}$ Due to the high mineral content of enamel, this latter effect should be considered when self-etching primers are applied on enamel. ${ }^{16}$

A recent study ${ }^{17}$ also tested acid etching before the application of 2 self-etching primers (Clearfil SE Bond and Unifil Bond). An increase in enamel bond strength and a decrease in dentin bond strength were observed. ${ }^{17}$ The values for Clearfil SE Bond applied on enamel were $14.3 \mathrm{MPa}$ for a single application and $20.5 \mathrm{MPa}$ with previous acid etching. ${ }^{17}$ In microscopic observations, the tags obtained with Clearfil SE Bond without previous acid etching had a lamina-like aspect with porous areas in demineralized areas. ${ }^{17}$ When Clearfil SE Bond was applied with previous acid etching for 15 seconds, tags infiltrated in decalcified areas were also observed, but they were thicker, with a fibrous aspect at their bases, and they were connected. ${ }^{17}$ Another study by the same authors ${ }^{18}$ observed a thicker extent of infiltrated tags in enamel after the application of a conventional adhesive system with previous acid etching, which indicated a more stable adhesion.

In this study, Clearfil SE Bond presented lower bond strength values when compared with the conventional adhesive system Scotchbond Multipurpose Plus. These findings were similar to those of another study ${ }^{19}$ that observed that Scotchbond Multipurpose Plus and Single Bond had higher bond strength values to bovine enamel than the self-etching primer Etch \& Prime (similar to Clearfil SE Bond).

Some studies have confirmed that self-etching primers had high dentin bond strength values, and that they have good clinical performance. ${ }^{20,21}$ Nevertheless, the self-etching primers have not surpassed conventional adhesives in enamel bond strength tests.

In the related literature, a comparison was also found between the enamel and dentin bond strengths of 3 adhesive systems: a self-etching adhesive (Prompt L-Pop); a self-etching primer (Clearfil SE Bond), and a conventional adhesive system (Prime \& Bond NT). The self-etching adhesive and self-etching primer showed higher enamel bond strengths than that of dentin., ${ }^{9,22}$

Another study compared the human enamel bond strength of the following adhesive systems: self-etching adhesives (iBond; Prompt L-Pop and Xeno III); a self-etching primer (Clearfil SE Bond) and a conventional adhesive system (Scotchbond Multipurpose Plus). The self-etching primer (Clearfil SE Bond) presented an enamel bond strength comparable to that of the conventional adhesive system. ${ }^{23}$ The re- 
ported advantage was that the self-etching primer promoted high bond strength with minimal changes in the enamel surface topography when compared with conventional systems, resulting in an additional secondary adhesion. ${ }^{23}$ Although this is an additional factor to increase bond strength, it is uncertain whether this secondary adhesion promoted by self-etching primers has the same long term stability as the bond produced by the micromechanical retention of conventional adhesive systems. ${ }^{23}$

There is another study ${ }^{24}$ that compared the enamel bond strength of 4 self-etching adhesives (AdheSE, Adper Prompt L-Pop, Clearfil SE Bond, Tyrian SPE/ One Step Plus) with that of a conventional adhesive system (Prime \& Bond NT). The pH values of the self-etching solutions and of phosphoric acid were measured with the purpose of relating $\mathrm{pH}$ to bond strength. ${ }^{24}$ The self-etching adhesives Adper Prompt L-Pop and Clearfil SE Bond had bond strength values similar to those of the conventional adhesive systems, only when the time recommended by the manufacturer was doubled. ${ }^{24}$ When the application time of Clearfil SE Bond was changed from 30 to 60 seconds, an increase in enamel bond strength was observed. ${ }^{17}$ It was concluded that the $\mathrm{pH}$ of Clearfil SE Bond was not acid enough to dissolve hydroxyap-

\section{References}

1. Shono T. Pulpal responses to light-cured restorative glass polyalkenoate cements, and ultrastructure of cement-dentin interface. Japan J Conserv Dent. 1995;38:514-48.

2. Ferrari M, Mannocci F, Vichi A, Davidson CL. Effect of two etching times on the sealing ability of Clearfil Liner Bond 2 in class V restorations. Am J Dent. 1997;10(2):66-70.

3. Perdigão J, Lopes L, Lambrechts P, Leitão J, Van Meerbeek B, Vanherle G. Effects of a self-etching primer on enamel shear bond strengths and SEM morphology. Am J Dent. 1997;10(3):141-6.

4. Cardoso P, Carrilho M, Francci C, Perdigão J. Microtensile bond strengths of one-bottle dentin adhesives. Am J Dent. 2001;14(1): 22-4.

5. Watanabe I. Photocure bonding agents to ground dentin. Jpn J Dent Mater. 1992;11:955-73.

6. Nakanuma K, Arisue K, Kajiwara M, Niinuma A, Murakami Y, Yamazaki M. Evaluation of new types of commercially available adhesive systems - effect of total treatment for enamel and dentin. Japan J Conserv Dent. 1996;39:304-14. atite crystallites as deeply, when compared with the dissolution depth obtained with phosphoric acid. ${ }^{24}$

It could, thus, be argued that, in this study, a previous acid etching did not produce sufficient dissolution of apatite crystals to improve the bond to enamel of the self-etching primer. Moreover, both when the self-etching primer was used according to the original prescription and with previous acid etching, it presented a thin extent of infiltrated tags in enamel, which resulted in unstable adhesion. Therefore, the application of a conventional adhesive system in both enamel and dentin is considered safer because of the greater depth of apatite crystal dissolution and thicker extent of infiltrated tags, which was confirmed by the higher bond strength values obtained in this study.

\section{Conclusion}

The self-etching primer (Clearfil SE Bond) presented lower enamel bond strength values than the conventional adhesive system (Scotchbond Multipurpose Plus), both when applied according to the original prescription and with previous acid etching. Therefore, the previous enamel etching did not improve enamel adhesion of the self-etching primer adhesive.

7. Nakamichi I, Iwaku M, Fusayama T. Bovine teeth as possible substitutes in the adhesion test. J Dent Res. 1983;62(10):107681.

8. Perdigão J, Geraldeli S, Carmo AR, Dutra HR. In vivo influence of residual moisture on microtensile bond strengths of one-bottle adhesives. J Esthet Restor Dent. 2002;14(1):31-8.

9. Kiremitçi A, Yalçin F, Gökalp S. Bonding to enamel and dentin using self-etching adhesive systems. Quintessence Int. 2004;35(5):367-70.

10. Miyazaki M, Sato M, Onose H, Moore BK. Influence of thermal cycling on dentin bond strength of two-step bonding systems. Am J Dent. 1998;11(3):118-22.

11. Perdigão J, Francci C, Swift EJ, Ambrose WW, Lopes M. Ultramorphological study of interaction of adhesives with carbamide peroxide bleached enamel. Am J Dent. 1998;11(6):291301.

12. Sano H, Takatsu T, Ciucci B, Horner JA, Matthews WG, Pashley DH. Nanoleakage: Leakage within the hybrid layer. Oper Dent. 1994;20(1):18-25. 
13. Miyazaki M, Sato H, Onose H, Moore BK, Platt JA. Analysis of the enamel/adhesive resin interface with laser Raman microscopy. Oper Dent. 2003;28(2):136-42.

14. Cardoso PEC, Plácido E, Francci CE, Perdigão J. Microleakage of Class $\mathrm{V}$ resin-based composite restorations using five simplified adhesive systems. Am J Dent. 1999;12(6):291-4.

15. Opdam NJ, Roeters FJ, Feilzer AJ, Verdonschot EH. Marginal integrity and postoperative sensitivity in Class II resin composite restoration in vivo. J Dent. 1998;26(7):555-62.

16. Yoshiyama M, Carvalho RM, Sano H, Horner JA, Brewer PD, Pashley DH. Regional bond strengths of resins to human root dentine. J Dent. 1996;24(6):435-42.

17. Torii Y, Itou K, Nishitani Y, Ishikawa K, Suzuki K. Effect of phosphoric acid etching prior to self-etching primer application on adhesion of resin composite to enamel and dentin. Am J Dent. 2002;15(5):305-8.

18. Torii Y, Itou K, Hikasa R, Iwata S, Nishitani Y. Enamel tensile bond strength and morphology of resin-enamel interface created by acid etching system with or without moisture and self-etching priming system. J Oral Rehabil. 2002;29(6):52833.
19. Gordan VV, Vargas MA, Denehy GE. Interfacial ultrastructure of the resin-enamel region of three adhesive systems. Am J Dent. 1998;11(1):13-6.

20. Hara AT, Amaral CM, Pimenta LAF, Sinhoreti MAC. Shear bond strength of hydrophilic adhesive systems to enamel. Am J Dent. 1999;12(4):180-4.

21. Shimada Y, Senawongse P, Harnirattisai C, Burrow MF, Nakaoki Y, Tagami J. Bond strength of two adhesive systems to primary and permanent enamel. Oper Dent. 2002;27(4):4039.

22. Hannig M, Reinhardt KJ, Bott B. Self-etching primer vs. phosphoric acid: an alternative concept for composite-to-enamel bonding. Oper Dent. 1999;24(3):172-80.

23. Brackett W, Ito S, Nishitani Y, Haisch LD, Pashley DH. The microtensile bond strength of self-etching adhesives to ground enamel. Oper Dent. 2006;31(3):332-7.

24. Perdigão J, Gomes G, Lopes MM. Influence of conditioning time on enamel adhesion. Quintessence Int. 2006;37(1):3541. 